\title{
Medication-induced papilledema
}

\begin{abstract}
Abbreviations: MIPE, medication-induced papilledema; ICP, intracranial pressure; ICH, intracranial hypertension; OD, optic disc; $\mathrm{ONH}$, optic nerve head; CSF, cerebrospinal fluid; NFL, nerve fiber layer
\end{abstract}

\section{Editorial}

Papilledema is defined as optic disc (OD) edema secondary to elevated intracranial pressure (ICP). It usually involves in a symmetric manner in both optic nerve head(ONH)s. Papilledema cannot develop in the absence of the elevated ICP while as an elevation of ICP can occur in the absence of papilledema. ${ }^{1,2}$ The elevated ICP or intracranial hypertension (ICH) may be caused by the various pathogenic mechanisms including the increase in intracranial tissue volume or amount by the cerebral edema or an intracranial spaceoccupying lesion such as brain tumor or hemorrhage or aneurysm; an increase of CSF production by choroid plexus; the decrease in the ventricular CSF outflow such as obstructive/non-communicating hydrocephalus or meningitis and subarachnoid hemorrhage; and a decrease in the CSF absorption by arachnoid villi or compromise of venous outflow (cavernous venous sinus thrombosis) or an elevation of intra-abdominal pressure resulting in an elevation in pleural pressure and cardiac filling pressure. ${ }^{3-6}$ The visual symptoms of papilledema include typically transient visual obscurations lasting seconds due to transient fluctuations in $\mathrm{ONH}$ perfusion. If it remains untreated, it can cause progressive irreversible visual loss and optic atrophy. The fundus findings of papilledema vary to its stages. Frisén scale for papilledema grading includes six stages ranging from " 0 " to " 5 ": $1,2,7$

Stage 0 defines a "Normal optic disc" with blurring of nasal, superior, and inferior poles in inverse proportion to OD diameter (Stage 0A); radial nerve fiber layer (NFL) without NFL tortuosity (Stage 0B); rare obscuration of a major vessel, usually on the upper pole (Stage 0C). ${ }^{1,2,7}$ Stage 1 defines a "Very early papilledema" with the obscuration of the nasal border of the OD (Stage 1A); no elevation of OD borders (Stage 1B); the disruption of the normal radial NFL arrangement with grayish opacity accentuating nerve fiber bundles (Stage 1C); a normal temporal OD margin (Stage 1D); the subtle grayish halo with temporal gap (Stage 1E); concentric/radial retinochoroidal folds (Stage 1F). ${ }^{1,2,7}$ Stage 2 defines an "Early papilledema" with the obscuration of all borders of OD (Stage 2A); the elevation of the nasal border of OD (Stage 2B); a complete peripapillary halo (Stage 2C). ${ }^{1,2,7}$

Stage 3 defines "'Moderate papilledema" with the obscuration of all borders of OD (Stage 3A); the elevation of all borders of OD (Stage 3B); the increased diameter of OD (Stage 3C); the obscuration of one or more segments of major blood vessels leaving OD (Stage 3D); and peripapillary halo: irregular outer fringe with fingerlike extensions (Stage 3E). ${ }^{1,2,7}$

Stage 4 means a "Marked papilledema" with the elevation of entire OD (Stage 4A); the obscuration of all OD borders (Stage 4B); peripapillary halo (Stage 4C) and the total obscuration on OD of a segment of a major blood vessel (Stage 4D). ${ }^{1,2,7}$ Stage 5 means 'Severe papilledema". The dome-shaped protrusions, representing the anterior expansion of the ONH may be observed (Stage 5A). Peripapillary
Volume 9 Issue 4 - 2019

\author{
Burak Turgut \\ Faculty of Medicine, Department of Ophthalmology, Onsekiz Mart \\ University, Turkey \\ Correspondence: Burak Turgut, Faculty of Medicine, Department \\ of Ophthalmology, Onsekiz Mart University, Turkey, Tel +90533 \\ 7128389,Email burakturgut@comu.edu.tr
}

Received: July 03, 2019 | Published: August 06, 2019

halo seems as narrow and smoothly demarcated (Stage 5B). Total obscuration of a segment of a major blood vessel may or may not be present (Stage 5C). Stage 5D defines the obliteration of the optic cup. . $^{1,2,7}$ Pseudotumor cerebri or idiopathic or benign ICH is defined as elevated ICP with a normal cerebrospinal fluid (CSF) composition associated with papilledema in the absence of the localizing neurological signs, except for unilateral or bilateral sixth nerve palsies, and the absence of an identified etiology such as hydrocephalus, mass, structural, or vascular lesion on imaging or other etiologic cause for ICH..$^{3-6}$ Recent reports demonstrated that some medications have caused or associated with drug- or medication-induced papilledema (MIP). ${ }^{8-31}$ Common medications which have anecdotal or strong evidence related with MIP in current literature are corticosteroids (prolonged therapy or withdrawal), hormones such as cyclosporine, leuprorelin acetate (LH-RH analog), growth hormone (GH, levothyroxine) or thyroid hormone (replacement), or estrogen (levonorgestrel); some antibiotics such as sulfa-antibiotics, tetracyclines (minocycline and doxycycline), nitrofurantoin and nalidixic acid; vitamin A analogs (retinoids) used in dermatological and cancer therapy such as liver cis-retinoic acid, all-trans-retinoic acid, retinol, isotretinoin, etretinate, and tretinoin; some antipsychotics such as lithium, fluvoxamine, sertraline and mirtazapine; and an antiepileptic drug-like, phenytoin. Tetracyclineinduced papilledema usually occurs within a few weeks to months after the onset of treatment while as GH-induced papilledema usually develops within one year of initiation of therapy..$^{8-31}$

\section{Conclusion}

In this editorial, it was aimed to remind ophthalmologists about the main causes of MIP.

\section{Acknowledgments}

None.

\section{Conflict of interest}

The author declares that there is no conflict of interest regarding the publication of this paper.

\section{Authorship contributions}

The author has contributed to the concept and design, data collection, literature Search in the work and writing of the manuscript. 


\section{References}

1. Rigi M, Almarzouqi SJ, Morgan ML, et al. Papilledema: epidemiology, etiology, and clinical management. Eye Brain. 2015;7:47-57.

2. Bienfang DC. Overview and differential diagnosis of papilledema Uptodate. 2019.

3. Lee AG, Wall M. Idiopathic intracranial hypertension (pseudotumor cerebri): Epidemiology and pathogenesis. Uptodate. 2019.

4. Thurtell MJ, Wall M. Idiopathic intracranial hypertension (pseudotumor cerebri): recognition, treatment, and ongoing management. Curr Treat Options Neurol. 2013;15(1):1-12.

5. Friedman DI. The Pseudotumor Cerebri Syndrome. Neurologic Clinics 2014;32(2):363-396.

6. Burkett JG, Ailani J. An Up to Date Review of pseudotumor cerebri syndrome. Curr Neurol Neurosci Rep. 2018;18(6):33.

7. Frisén L. Swelling of the optic nerve head: a staging scheme. J Neurol Neurosurg Psychiatry. 1982;45(1):13-18.

8. Thon OR, Gittinger JW Jr. Medication-related pseudotumor cerebr syndrome. Surv Ophthalmol. 2017;32(1):134-143.

9. von Wolff A, Hölzel LP, Westphal A, et al. Selective serotonin reuptake inhibitors and tricyclic antidepressants in the acute treatment of chronic depression and dysthymia: A systematic review and meta-analysis. $J$ Affect Disord. 2013;144(1-2):7-15.

10. Ceylan ME, Evrensel A, Cömert G. Papilledema due to mirtazapine. Balkan Med J. 2016;33(3):363-365.

11. Hutcheon ML. An unexpected case of swollen optic nerves. Am J Ther 2011;18(4):e126-e129.

12. Kelly SJ, O’Donnell T, Fleming JC, et al. Pseudotumor cerebri associated with lithium use in an 11-year-old boy. J AAPOS. 2009;13(2):204-206.

13. Greer M. Benign intracranial hypertension. II. Following corticosteroid therapy. Neurology. 1963;13(5):439-441.

14. Cruz OA, Fogg SG, Roper-Hall G. Pseudotumor cerebri associated with cyclosporine use. Am J Ophthalmol. 1996;122(3):436-437.

15. Blethen SL. Complications of growth hormone therapy in children. Curr Opin Pediatr. 1995;7(4):466-471

16. Francois I, Casteels I, Silberstein J, et al. Empty sella, growth hormone deficiency and pseudotumour cerebri: effect of initiation, withdrawal and resumption of growth hormone therapy. Eur J Pediatr. 1997;156(1):69-70.
17. Boot JH. Pseudotumor cerebri as a side effect of leuprorelin acetate. Ir $J$ Med Sci. 1996;165(1):60.

18. Campos SP, Olitsky S. Idiopathic intracranial hypertension after L-thyroxine therapy for acquired hypothyroidism. Clin Pediatr. 1995;34(6):334-337.

19. Saul RF, Hamburger HA, Selhorst JB. Pseudotumor cerebri secondary to lithium carbonate. JAMA. 1985;253(19):2869-2870.

20. Cohen DN. Intracranial hypertension and papilledema associated with nalidixic acid therapy. Am J Ophthalmol. 1973;76(5):680-682.

21. Wysowski DK, Green L. Serious adverse events in Norplant users reported to the Food and Drug Administration's MedWatch spontaneous reporting system. Obstet Gynecol. 1995;85(4):538-542.

22. Alder J, Fraunfelder F, Edwards R. Levonorgestrel implants and intracranial hypertension. N Engl J Med. 1995;332(25):1720-1721.

23. Gardner K, Cox T, Digre K. Idiopathic intracranial hypertension associated with tetracycline use in fraternal twins: case report and review. Neurology. 1995;45(1):6-10.

24. Walters BN, Gubbay SS. Tetracycline and benign intracranial hypertension: report of five cases. Br Med J (Clin Res Ed). 1981;282(6257):19-20.

25. Chiu AM, Chuenkongkaew WL, Cornblath WT, et al. Minocycline treatment and pseudotumor cerebri syndrome. Am J Ophthalmol. 1998;126(1):116-121.

26. Lochhead J, Elston JS. Doxycycline induced intracranial hypertension. BMJ. 2003;326(7390):641-642.

27. Lombaert A, Carton H. Benign intracranial hypertension due to A-hypervitaminosis in adults and adolescents. Eur Neurol. 1976;14(5):340-350.

28. Fraunfelder FW, Fraunfelder FT, Edwards R. Ocular side effects possibly associated with isotretinoin usage. Am $J$ Ophthalmol. 2001;132(3):299-305.

29. Lebowitz MA, Berson DS. Ocular effects of oral retinoids. J Am Acad Dermatol. 1988;19(1 Pt 2):209-211.

30. Fraunfelder FW, Fraunfelder FT, Corbett JJ. Isotretinoin-associated intracranial hypertension. Ophthalmology. 2004;111(6):1248-1250.

31. Viraben R, Mathieu C, Fontan B. Benign intracranial hypertension during etretinate therapy for mycosis fungoides. $J$ Am Acad Dermatol. 1985;13(3):515-517. 